\title{
Impact of Rewards and Leadership on the Employee Engagement in Conventional Banking Sector of Southern Punjab
}

\author{
Benazir, Dr Nadeem Iqbal \\ Faculty of Management Science, Indus International Institute DG Khan \\ Faculty of Management Science, Ghazi University DG Khan \\ E-mail address: drnadeemiqbal1@gmail.com
}

Keywords: Impact of Rewards; Leadership; Employee Engagement

\begin{abstract}
The purpose of this research is to explore the impact of rewards and leadership on the employee engagement in conventional banking sector of southern Punjab. Employee engagement is fully influenced by leadership, workplace culture, company reputation and reward practices. Satisfied workers have potential to work effectively and they always remain loyal to the organization. This research focuses to evaluate the impact of two covariates reward and leadership on the engagement of the employees. The data includes 50 employees of 5 banks selected from conventional banking sector located in southern Punjab. The results indicate positive impact of reward and leadership on employee engagement. The paper provides evidence to suggest that management focus to enhance skills of the employees through proper coaching, leadership, and motivation.
\end{abstract}

\section{INTRODUCTION}

In today's competitive marketplace employee engagement has emerged as a critical driver of business success. Further, in organizational success employee engagement can be a deciding factor not only for retaining employees, productivity and loyalty but also effect customer satisfaction, company reputation and overall stakeholder value. Engaged workers have extraordinary intensities of vitality, are excited about their exertion and are a lot completely absorbed in their profession so that period flutters (Macey and Schneider, 2008; May et al., 2004).

It is observed that employees do not automatically come to work, continue to work, or work hard for an organization. It is observed that employees show enthusiasm to share and fulfill the organization's vision. The primary focus of employee engagement efforts has mostly been on teambuilding programs, employee opinion surveys and nonfinancial rewards, egalitarian pay structures have been found to be related to employee satisfaction, participation, performance productivity and commitment which have been used as substitute for employee engagement.

To engage the employees in the organization, management should provide the skills to the employees through proper coaching, leadership, motivation, and give appraisals that the employees will perform efficiently and effectively and up to the mark of achieving the organizations goals and missions. Organization is in the position to motivate the employees and to engage them in the organization to accomplish their talent management objectives and goals.

The most effective strategy is reward system and leadership of the organization to engage the employees in the organizational goals and to manage performance of an individual or a group. The best way is to appraise and give a raise in something and it could be a monitory raise or some kind of recognition among others. Rewards can have a great impact on engaging employees within the organization. It is observed that engaging employees within organization is a very complex process but management must take time to fully develop it.

Reward systems should be aligned with the company's goals and objectives, employee development, company's strategies and team performance. In order to create a competitive edge organization should maintain the reward system within the organization so that employees work hard and efficiently perform in their work. In the company these programs usually train and inspire associates to become more productive, efficient and respected individuals. 
Employee engagement is fully influenced by leadership, workplace culture, company reputation and reward practices. Engaged workers work very hard and loyal to their organization. Thus, to raise the values and principles of engagement, HR must design programs and practices for the employees in whom they connect in their work and feel committed to their organization and its goals and objectives. So the employees perform well in the organization.

This research discovers the gap and concludes how total rewards programs and employee engagement are associated in conventional banking sector of DG Khan Division, Southern Punjab. It also helps to define whether total rewards programs are related with organization performance by focusing on the following questions:

- Which reward policies are related with employee engagement?

- Does involvement of the reward practices enhance employee engagement?

- Is employee engagement is related with organization performance?

This study has two types of research questions which develop the relationship between reward and engagement attributes and activities that enhance organization performance and the other is importance of leadership skills that enhance leadership abilities and how these abilities lead to improve employee's personal growth and organizational performance.

\section{LITERATURE REVIEW}

Stanislavov and Inavov (2014) revealed that the impact of leadership styles on employee's engagement and organizational performance. That leadership styles led to significant changes on employees and organization culture. The results showed that the visionary style creates the highest level of engagement while commanding and pacesetting styles create the lowest. It was also proposed that the leader must consider the maturity level of the followers and undertake the appropriate leadership style that fits this level.

Mehmood et al. (2013) indicated that based on reward system that the research is carried out through constructive analysis from different papers and articles. Through reward practices engaging employees and managing performance in the organization is very easy for the management. To boost the performance up to the organizational needs and demands it enables to understand the current needs of the employees and their low productivity and performance in the organization.

Iqbal et al. (2013) investigated that employee engagement creates a positive relationship between co-workers inside the company that improves the performance of the employment for the profit of the organization. That is the level of involvement and commitment of the employees to the organization and its principles. This paper emphasis on the engagement policies which increase the organizational efficiency in relation of production, revenue excellence, buyer gratification and employee preservation.

San et al. (2012) showed that to enhance organization reputation and also to boost the recruitment possibility where more manpower will make a stronger team within organization through rewards that lead both financial and non-financial performance of the employees in the company. Effective reward strategies not only fulfilling the employee's basic requirement but also increase their engagement in the organization that is a growing signal for the organization. It indicates that rewards are most important element to engaging employees for contributing their best effort to generate innovative ideas to enhance the company performance both financially and nonfinancially. According to researcher, to develop and design programs which will ensure its rewards the performance outcomes supporting the achievement of its business goals. Reward strategy is the policy that provides specific directions for the organization. Various studies have shown positive results on the effect of reward structures on the performance measure.

Voon et al. (2011) showed that transformational leadership style has a stronger and positive relationship with job satisfaction and employee engagement. Leaders can affect employee engagement, satisfaction, commitment, performance and productivity by adopting the suitable leadership styles with employees. Furthermore leadership is a process that influences employees and leaders where a leader attempts to influence the behavior of subordinates to achieve the 
organizational goals. By achieving the organizational goals and objectives, the organization success depend on the leader and its leadership styles.

Mujtaba and Shuaib (2010) discussed that how organizational rewards enhance the good work habits and significant boost the performance of each employee. Through reward strategies management can attract a pool of qualified candidates and maintain a highly motivated workforce in the organization. Successful companies use the rewards programs to motivate and retain the top talent and good employee performance which is strategically aligned with the organization's values and objectives. Employees will regularly think of quality in their work which may lead to better ways of doing the job if organizations and managers reward quality products and quality improvement, then. Organizations should reward customers confidence and satisfaction, employees will definitely modify their behavior to build a good relationship with customers in order to know and satisfy their needs.

Men (2010) examined the links between the leadership styles, employee empowerment on organizational leadership on public relations effectiveness from an external perception of organizational reputation. Through empowering employees in organization it showed that leadership positively influence not directly but also indirectly employee's perception of organizational reputation. In transformational leadership, management delegate power to employees and involve them in decision making than transactional leadership. In a more favorable and encouraging evaluation of organizational reputation employees feel more convenient and empowered in terms of competence and performance.

\section{Methodology}

The paper used primary data to analyze the impact of leadership and reward on employee commitment and engagement to their organization. In this research study, the target population includes NBP, HBL, ABL, BOP and MCB situated in DG KHAN. In this study responses were collected through questionnaire about the various aspects of reward management and employee engagement and have been analyzed, using certain statistical measures. The paper concluded the positive relationship with employee engagement. Descriptive result of the study is as under.

\section{Results}

\section{Respondents Profile}

\begin{tabular}{lll}
\hline Gender & Male & 41 \\
& Female & 9 \\
\hline Age & $21-25$ & 4 \\
& $26-30$ & 16 \\
& Above 30 & 30 \\
\hline Education & Under Graduate & 2 \\
& Graduate & 19 \\
& Post Graduate & 29 \\
\hline Banks & NBP & 10 \\
& HBL & 10 \\
& BOP & 10 \\
& ABL & 10 \\
& MCB & 10
\end{tabular}

In this research, the respondents profile is categorized into demographic factors through the descriptive statistics. Gender in which there are 41 male and 9 female which are categorized into three different age levels. There are 4 respondents which are between 21-25 years of old, 16 between 26-30 and 30 which are above age of 30. Educational level is also categorized into three levels in which 2 employees are under-graduate, 19 graduate and 29 individuals are post-graduate. 
Descriptive Statistics

\begin{tabular}{llllll}
\hline & $\mathrm{N}$ & Minimum & Maximum & Mean & St.Deviation \\
\hline Reward & 50 & 1.30 & 3.10 & 2.2200 & .37253 \\
Leadership & 50 & 1.14 & 3.00 & 2.0343 & .44390 \\
Emp.Engagement & 50 & 1.29 & 3.14 & 2.0171 & .47480
\end{tabular}

The above table shows the description provides summary statistics of Mean and St.deviation of the variables.

\section{Correlation}

\begin{tabular}{|c|c|c|c|c|}
\hline & & Reward & Leadership & Engagement \\
\hline Reward & $\begin{array}{l}\text { Pearson } \\
\text { Correlation }\end{array}$ & 1 & & \\
\hline Leadership & $\begin{array}{l}\text { Pearson } \\
\text { Correlation }\end{array}$ & .174 & 1 & \\
\hline Engagement & $\begin{array}{l}\text { Pearson } \\
\text { Correlation }\end{array}$ & $.283^{*}$ & $.355^{*}$ & 1 \\
\hline
\end{tabular}

The correlation analysis used to analyze the relationship between the two independent variables Reward and Leadership with dependent variable Employee Engagement. As shown in above table, the correlation between two independent variables Reward and Leadership has .174 which shows significant positive relationship. Reward the independent variable and Employee Engagement the dependent variable shows the correlation .283 which has a positive influence and the Leadership and Employee Engagement .355 shows the significant positive correlation.

\section{Coefficients}

\begin{tabular}{|c|c|c|c|c|c|}
\hline \multirow[t]{2}{*}{ Model } & \multicolumn{2}{|c|}{$\begin{array}{l}\text { Unstandardized } \\
\text { Coefficients }\end{array}$} & \multirow{2}{*}{$\begin{array}{l}\text { Standardized } \\
\text { Coefficients } \\
\text { Beta }\end{array}$} & \multirow[t]{2}{*}{$\mathrm{t}$} & \multirow[t]{2}{*}{ Sig. } \\
\hline & $\mathrm{B}$ & Std. Error & & & \\
\hline (Constant) & .685 & .442 & & 1.550 & .128 \\
\hline REWARD & .291 & .171 & .228 & 1.699 & .096 \\
\hline leadership & .337 & .144 & .315 & 2.344 & .023 \\
\hline
\end{tabular}

The influence of Reward on Employee Engagement as shown in above Table, $\beta=.291, t=1.699$, $\mathrm{p}=.096>0.05$ which is partially supported, it means that Reward has positive influence on Employee Engagement at a certain level but not a significant level.

As shown in above table $\beta=.685, \mathrm{t}=2.344, \mathrm{p}=0.23<0.05$ which has a highly statistical significance, it means that Leadership has positive influence on Employee Engagement.

\section{DISCUSSION}

In this paper results indicate that there is a positive relationship of both reward and leadership on engagement of employees within the organization. It also shows that engagement of employees is significantly correlated with leadership and there is a positive effect of leadership on employee engagement. The organization performance connects the employee's skills to organizational leadership and reward management. 
From research study it explores that employees are more convenient and want supportive communication from their leaders. It is concluded that organizational leadership needs to help their subordinates and give employees an effective rewards that motivate the employees towards their works and company's performance. Engagement is a two-way process between employees and an organization. Engaged employees have their hearts and minds aligned with the job they do and the organization they work for. Engaged employees display the commitment and satisfaction to the job and organization.

\section{CONCLUSION}

Analysis revealed that leadership enhance and promote employee engagement and it is a positive emotional connection to an employees work. Positive effect of reward and organizational leadership are associated with higher level of engagement. Organization commitment to reward and leadership is important for employee engagement and motivation for employees to work hard within organization. Engagement of employees with their work and organization improve the level of performance. Engaged employees are inspired to go beyond, support the association to accomplish its tasks and plan and boost up the company to meet the business goals.

\section{References}

[1] Iqbal, N., Javaid, K., Ahmad, N., \& Ateeq, M., (2013), Impact of Rewards and Leadership on the Employee Engagement: A Case Study from Banking Sector of Pakistan, Management and Administrative Sciences Review ISSN: 2308-1368 Volume: 2, Issue: 4, Pages: 379-390 (2013)

[2] Macey, W. H., \& Schneider, B. (2008). The meaning of employee engagement.Industrial and organizational Psychology, 1(1), 3-30.

[3] Mehmood, S.,Ramzan, M., \& Akbar, M.(2013). Journal of Education \& Research for Sustainable Development, (An Online Quarterly International Peer-Reviewed Interdisciplinary Journal of Seven Petals Foundation) Volume-1, Online Issue-1

[4] Men, L, (2010), Measuring the Impact of Leadership style and Employee Empowerment on Perceived Organizational Reputation, Submitted to the Institute for Public Relations, For the 2010Ketchum Excellence in Public Relations Research Award, (973)-818-8801

[5] Mujtaba, B. G., \& Shuaib, S. (2010). An equitable total rewards approach to pay for performance management. Journal of Management Policy and Practice,11(4), 11-121.

[6] San,O.,Theen, Y.,Heng, T.(2012), The Reward Strategy and Performance Measurement (Evidence from Malaysian Insurance Companies), International Journal of Business, Humanities and Technology Vol. 2 No. 1; January 2012

[7] Stanislavov,I., \& Ivanov,S.(2014). The role of leadership for shaping organizational culture and building employee engagement in the Bulgarian gaming industry, original scientific paper, Vol. 62/ No. 1/ 2014/ 19 - 40, UDC: 338.486.3(497.2)

[8] Voon, M., Lo, M., Ngui1, K., \& Ayob, N.(2011), The influence of leadership styles on employees' job satisfaction in public sector organizations in Malaysia, International Journal of Business, Management and Social Sciences Vol. 2, No. 1, 2011, pp. 24-32 